\title{
PERANCANGAN PROSES PRA PRODUKSI FILM ANIMASI 3D LEGENDA PUTRI MERAK JINGGA
}

\author{
Neni Mulyani \\ Program Studi Sistem Informasi, STMIK Royal Kisaran \\ E-mail: neni.muliani@gmail.com
}

\begin{abstract}
Abstrack:To produce a 3D animated film requires a long process flow so that the processing time of manufacture is also prolonged. This is a constraint in the development of the local animation film in Indonesia for a long time will lead to high production costs making it difficult to compete commercially with animated films from abroad who have abundant funds and the support of various parties in the country. Therefore, efforts to improve the competitiveness of local animated film and one of these efforts is by analyzing the stages of the manufacturing process and apply it to the process of making the actual 3D animated film.In general there are three stages of the filmmaking process, namely the 3D animation preproduction, production and post-production. Although this time the animation industry in Indonesia has not been detailed separates each of these stages, but still be important for designing detail the activities of these stages, in order to see the strengths and weaknesses of each process that existed at that stage. Therefore, this study was conducted with the hope to provide recommendations to improve the local animation industry.
\end{abstract}

Keywords: 3D Animation, Animation Film Pre-Production Stage, Princess Peacock Orange

\begin{abstract}
Abstak: Untuk menghasilkan sebuah film animasi 3D membutuhkan alur proses yang panjang sehingga waktu pembuatannya juga berlangsung lama. Ini yang menjadi kendala dalam perkembangan film animasi lokal di Indonesia karena waktu yang yang panjang akan mengakibatkan tingginya cost production sehingga sulit untuk bersaing secara komersial dengan film animasi dari luar negeri yang memiliki dana berlimpah dan dukungan dari berbagai pihak di negaranya. Untuk itu diperlukan upaya untuk meningkatkan daya saing film animasi lokal dan salah satu upaya tersebut adalah dengan menganalisa tahapan-tahapan proses pembuatan dan menerapkannya pada proses pembuatan film animasi 3D yang sebenarnya.Secara umum ada 3 tahapan proses pembuatan film animasi 3D yaitu pra produksi, produksi dan paska produksi. Meskipun saat ini industri animasi di Indonesia belum secara detail memisahkan setiap tahapan tersebut, namun tetap menjadi penting untuk merancang detail aktifitas dari tahapan tersebut, dengan tujuan untuk melihat kekuatan dan kelemahan dari setiap proses yang ada pada tahapan tersebut.
\end{abstract}

Kata Kunci: Animasi 3D, Tahap Pra Produksi Film Animasi, Putri Merak Jingga 


\section{PENDAHULUAN}

Animasi adalah salah satu sektor industri kreatif yang memiliki potensi ekonomi yang sangat baik. Hal ini dibuktikan dengan terus meningkatnya pertumbuhan dari sektor ini, yaitu sekitar $10 \%-15 \%$ per tahun dengan market size sekitar Rp. 5 triliun. Meski termasuk besar namun angka ini masih jauh tertinggal dari industri animasi di India dengan market size sebesar Rp 14 triliun dan pertumbuhan sebesar $30 \%$ tiap tahun [1].

Jika mengacu pada keberhasilan negara-negara berkembang lainnya terhadap perkembangan industri animasi, salah satu faktor penting yang dapat menjadikan industri animasi lokal mampu bersaing adalah dukungan dari pemerintah dalam hal regulasi atau kebijakan terkait animasi dari berbagai elemen. Untuk dapat terus meningkatkan pertumbuhan pada sektor animasi dibutuhkan dukungan. Dengan adanya dukungan tersebut diharapkan dapat menghasilkan sebuah produk yang berdaya saing.

Daya saing suatu produk dapat dianalisis dengan cara menjalankan langsung pembuatan produk tersebut sehingga dapat dilihat kekuatan dan kelemahan dari setiap proses yang ada.

Secara garis besar tahapan proses produksi film animasi 3D terbagi menjadi tiga tahapan, di antaranya adalah tahapan pra produksi, produksi dan paska produksi. Namun kondisi industri animasi di Indonesia saat ini belum melakukan spesialisasi secara khusus terhadap tahapan tersebut. Umumnya industri animasi melakukan tahapan tersebut secara keseluruhan [2].

Berdasarkan latar belakang dan kondisi tersebut kajian ini dilakukan dengan tujuan untuk mengetahui kelemahan dan kelebihan yang terjadi pada setiap tahapan produksi film animasi 3D. Namun ruang lingkup yang akan dibahas pada kajian ini hanya mencakup pada tahapan pra produksi pembuatan film animasi 3D Legenda Putri Merak Jingga.

Animasi 3D adalah animasi yang berwujud tiga dimensi meskipun bukan dalam bentuk 3D yang sebenarnya, yaitu bukan fisiknya, namun dalam wujud 3D dalam layar kaca 2D (layar tv, bioskop, komputer, proyektor dan media sejenisnya). Animasi 3D dapat didefinisikan sebagai animasi yang dapat dilihat dari berbagai sudut pandang (point of view) [3].

Tahapan animasi 3D secara keseluruhan dikerjakan dengan media komputer, mulai dari tahap modeling, texturing, lighting, sampai rendering. Keunggulan utama dari animasi 3D adalah visualisasi objek yang tampak lebih nyata dan mendekati bentuk aslinya. Keunggulan lain adalah kemampuannya untuk membuat dan mewujudkan visualisasi yang sulit dan tidak mungkin atau bahkan yang nampak mustahil. Kemampuan inilah yang dikembangkan dalam pembuatan film animasi 3D [4].

\section{Tahapan Pra Produksi Film Animasi 3D}

Produk animasi yang dihasilkan 
dapat berupa animasi 2D dan animasi 3D. Perbedaan yang signifikan dalam proses pembuatan animasi 2D dan 3D adalah pada tahapan produksi, dimana proses 2D tidak membutuhkan proses modelling, texturing dan lighting.

Proses pembuatan film animasi 3D secara umum dibagi menjadi tiga tahapan yaitu pra produksi, produksi dan paska produksi. Tahapan pra produksi adalah tahapan awal dalam proses pembuatan film animasi 3D. Tahapan ini sering juga disebut sebagai tahapan persiapan, karena pada tahapan ini persiapan administratif yang terkait sumber daya, jadwal dan anggaran dilakukan.

Pada tahapan ini juga ditentukan sukses atau tidak sebuah produk film animasi 3D, karena penentuan ide cerita dan konsep cerita dibuat pada tahapan ini, sehingga perlu dipersiapkan secara matang dan serius. Menurut Rio Victory Toar (2015) tahapan pra-produksi pembuatan film animasi 3D memiliki beberapa proses yang dapat dilihat pada gambar berikut:

Penjelasan dari setiap proses tersebut adalah sebagai berikut [5] :

1. Pengembangan ide cerita : pengumpulan ide-ide hingga menuangkannya dalam bentuk storyline.

2. Penulisan skenario: proses ini adalah proses pembuatan naskah atau alur cerita animasi. Skenario yang menarik akan menentukan keberhasilan dari film animasi yang dibuat. Skenario biasanya berbentuk teks tulisan /ketikan.

3. Proses manajerial: pada proses ini semua yang berkaitan dengan masalah administrasi seperti ketersediaan SDM yang sesuai dengan kompetensi, penyusunan kru, penyusunan jadwal dan penyusunan anggaran disusun dan dipersiapkan pada proses ini.

4. Concept art: berisi konsep untuk tiap-tiap elemen yang ada pada cerita, seperti bentuk karakter, bentuk tas, pakaian karakter dan sebagainya. Hal ini perlu digambarkan dengan detail oleh illustrator agar dapat dengan mudah dipahami oleh kru film yang bertugas mempersiapkan elemen-elemen tersebut (jika dalam animasi 3D, kru film yang dimaksud adalah modeller).

5. Storyboard: bentuk visual/gambar dari skenario yang telah dibuat, berupa kotak-kotak gambar (seperti komik) yang menggambarkan jalan cerita dan adegan-adegan yang hendak dibuat dalam film. Storyboard berfungsi sebagai panduan utama dari proses produksi animasi. Oleh karena itu, segala macam informasi yang dibutuhkan harus dibuat dan tercantum dalam storyboard, seperti angle kamera, tata letak/layout/staging, durasi, timing, dialog, ekspresi dan informasi lainnya. Dengan adanya storyboard, maka proses pembuatan animasi akan menjadi lebih mudah, 
jelas, fokus dan terarah.

\section{METODE}

Metode penelitian ini adalah kualitatif deskriptif dengan sumber data penelitian diperoleh dari sumber tertulis, narasumber dan dokumentasi dari cerita rakyat. Data dikumpulkan melalui studi pustaka dan karya, observasi, wawancara dan dokumentasi. Proses analisis data melalui beberapa tahapan, yaitu pengumpulan data, reduksi, sajian data, pengolahan data serta kesimpulan.

\section{PEMBAHASAN}

\section{Proses Pra Produksi}

Film animasi 3D legenda Putri Merak Jingga memiliki proses pra produksi sebagai berikut :

\section{Pengembangan ide cerita}

Berdasarkan pada penikmat film animasi yakni usia anak-anak, penyajian film animasi yang paling tepat menggunakan tipe alur maju. Berikut alur cerita/storyline film :

"Alkisah di kota Teluk Belanga terdapat sebuah kerajaan bernama Kerajaan Petani. Raja tersebut mempunyai dua orang anak yang bernama Putra Bandar Sakti yang perkasa dan Putri Merak Jingga yang elok rupawan. Kawan karib Putra Bandar Sakti bernama Alang Jermal, pemuda itu dicintai oleh Putri Merak Jingga.
Pada suatu hari Putra Bandar Sakti berkata kepada sahabatnya itu bahwa ia menginginkan seekor ikan yang paling enak dan belum diketahui oleh siapapun. Permintaan itu sebenarnya berasal dari adiknya, Merak Jingga. Sebagai kawan yang setia kepada junjungannya, Alang Jermal segera pergi mencari ikan itu. Sebagai anak pawang ikan, ia mengetahui seluk beluk laut. Akhirnya, dengan susah payah, ia berhasil menaklukan Jin Laut yang menjelma sebagai orang tua. Berkat bantuan orang tua itu, Alang Jermal memperoleh ikan yang diidamkan oleh Merak Jingga, kekasihnya. Sementara itu di kerajaan, ada rencana pemberontakan karena rakyat heboh memperbincangkan kepergian Alang Jermal dan dihasut oleh pengkhianat kerajaan, bahkan putri raja menjadi sakit karenanya. Syukurlah ia berangsur sembuh dan berbahagia ketika pemuda kekasihnya itu datang dan bercerita tentang kepergiannya mencari ikan itu".

Karena kebahagiaannya itu, memancarlah sinar terang dari parasnya hingga ke Negeri Tiongkok yang dipimpin oleh Raja Hwa Loan. Dan ternyata Raja Tiongkok yang sakti dan terkenal kejam itu mencintai gadis tersebut, sehingga terjadilah pertikaian antara Raja Hwa Loan dengan Alang Jermal dan mengakibatkan korban. Kerajaan Petani hancur dan raja bersama kakak Putri Merak Jingga tewas dibunuh Raja Tiongkok.

Untunglah Merak Jingga berhasil 
diselamatkan oleh Alang Jermal dari cengkraman Raja Tiongkok yang menjelma menjadi seekor naga besar itu. Akhirnya, Alang Jermal berhasil mempersunting Putri Merak Jingga.

\section{Penulisan skenario}

Proses berikutnya, dari alur cerita yang ada kemudian dilanjutkan dengan penulisan skenario yang menggambarkan rincian kejadian setiap adegan lalu dibagi menjadi beberapa scene. Untuk film ini terdiri beberapa scene antara lain :

\section{Scene ke 1}

Di suatu wilayah di Sumatera terdapat kota yang sangat ramai yaitu Kota Teluk Belanga. Di kota ini berdiri sebuah istana yang indah lagi jaya. (00.00-

00.10).

\section{Scene ke 2}

Istana itu adalah tempat tinggal Baginda Raja Tua Sakti bersama kedua orang anaknya Tuanku Putri Merak Jingga dan Tuanku Putra Bandar Sakti. Putri Merak Jingga memiliki wajah yang sangat cantik dan jelita, sedangkan abangnya putra Bandar Sakti terkenal sangat ramah, pemurah dan rendah hati. Ia sering bermain ke pantai bersama sahabatnya Alang Jermal anak dari seorang pawang laut. Dan ternyata adiknya telah jatuh hati kepada sahabatnya itu (00.10-00.20).

Scene ke 3

Suatu hari ketika mereka bermain di tengah laut, Putra Bandar Sakti berkata kepada Alang Jermal agar mencarikan ikan yang paling enak di dunia tetapi yang belum pernah diketahui orang. Mendengar permintaan temannya itu Alang Jermal pun lalu terjun ke dalam laut. Di dalam laut Alang Jermal bertemu Jin Laut sehingga terjadi pertarungan. Situasi pertarungan digambarkan terjadi dengan seru di bawah laut dan dimenangkan oleh Alang Jermal. Di permukaan terlihat Putra Bandar Sakti akhirnya pulang ke rumah karena Alang Jermal tidak muncul-muncul juga.

(00.20-00.30).

\section{Scene ke 4}

Terlihat sang putri bersedih setiap hari karena menganggap Alang Jermal telah meninggal sehingga akhirnya jatuh sakit. Wajahnya yang selama ini menyinarkan cahaya jingga kini telah pudar. Terlihat dukun dan tabib berganti-ganti mengobatinya tetapi penyakitnya tidak juga sembuh, bahkan semakin parah (00.30-00.45).

\section{Scene ke 5}

Digambarkan semua orang di istana menjadi cemas melihatnya, terlebihlebih abang dan ayahnya. Karena putus asa, pada suatu hari Baginda mengumumkan di muka Sidang Kerajaan bahwa barang siapa yang berhasil menyembuhkan penyakit Putri Merak Jingga akan dinikahkan dengannya. Datuk Tapa, salah seorang anggota Sidang, menyuruh sahabatnya Wan Tanjung untuk menyatakan kepada Baginda ia sanggup mengobati penyakit Putri Merak Jingga. Namun 
Datuk Tapa bukanlah seorang dukun, tetapi ia hanya bersandiwara karena hendak merebut kerajaan. Dan memang ia tidak berhasil menyembuhkan sang putri (00.45-00.55).

Scene ke 6

Pada suatu hari muncullah Alang Jermal di hadapannya. Sang putri langsung memeluk erat pujaan hatinya itu dan langsung sembuhlah sang putri dari sakitnya. Begitu senangnya hati sang putri sehingga memancarlah cahaya jingga dari wajahnya. (00.5501.10).

\section{Scene ke 7}

Pancaran cahaya dari wajah sang putri terlihat sampai ke Negeri Tiongkok. Yang pertama sekali melihat cahaya tersebut adalah Maharaja Hwa Loan yang langsung mengerahkan seluruh tentara kerajaannya mencari asal cahaya tersebut. Beberapa hari kemudian perwiranya melaporkan bahwa cahaya itu berasal dari wajah seorang putri yang sangat cantik. Mendengar itu timbul hasrat di hatinya untuk melamar putri yang cantik itu, lalu bertolaklah mereka ke arah selatan (01.10-01.30).

\section{Scene ke 8}

Sewaktu mereka berada di Selat Karimata, cahaya itu kelihatan menyinari dari arah barat sehingga armada itu segera menukar arah haluannya ke tempat asal cahaya itu. Tetapi tiba-tiba awan tebal menutupi laut. Untuk menghindari bahaya topan maka armada Hwa Loan berlabuh di Pulau Berhala di tempat Datuk Tapa dan temannya Wan Tanjung bersembunyi. Tentara Hwa Loan mengatakan maksud pelayaran mereka itu kepada Datuk Tapa Datuk Tapa yang banyak mengetahui tentang Putri Merak Jingga berjanji sanggup menyerahkan Putri Merak Jingga dengan syarat supaya Maharaja mengangkatnya menjadi raja yang sah di Kerajaan Petani. Dengan gembira Maharaja Hwa loan menyutujui usulnya (01.30-02.00).

\section{Scene ke 9}

Digambarkan pelantikan Datuk Tapa dan Wan Tanjung menjadi bangsawan di Tiongkok dengan nama yang baru yaitu Panglima TaFa dan Panglima Tan Yung. Selesai pelantikan tersebut armada Hwa Loan segera bertolak untuk menyerang kota Teluk Belanga (02.00-02.10).

\section{Scene ke 10}

Raja Tua Sakti Perkasa yang mendapat laporan bahwa Datuk Tapa datang hendak menyerangnya menyuruh pembesar-pembesar kerajaan agar kota dan istana dibakar seluruhnya (02.1002.25).

\section{Scene ke 11}

Tidak lama kemudian sampailah Maharaja Hwa Loan ke tempat yang dituju. Ia terkejut ketika melihat kota Teluk Belanga telah menjadi lautan api. Namun demikian, pendaratan tentara penggempu terus dilangsungkan dengan serunya. Panglima $\mathrm{Ta} \mathrm{Fa}$ dan Panglima Tian Yung berusaha mencari tempat persembunyian Putri Merak 
Jingga di sekitar istana yang terbakar itu. Tiba-tiba muncullah Putra Bandar Sakti menghadang di hadapan mereka. Dalam pertempuran yang dahsyat itu tewaslah Panglima Ta Fa dan Panglima Tan Yung. Diperlihatkan akhirnya kota Teluk Belanga jatuh ke tangan Maharaja Hwa Loan tanpa mendapat serangan balasan (02.25-02.40).

\section{Scene ke 12}

Pada suatu hari Maharaja Hwa Loan menyuruh seorang penduduk menghadap Raja Tua Sakti untuk melamar Putri Merak Jinga, tetapi lamarannya ditolak raja. Mendengar bahwa lamarannya ditolak oleh raja Tua Sakti Perkasa maka Maharaja Hwa Loan menjadi Murka. Segera dikerahkan tentaranya menyerang kembali. Putra Bandar Sakti menghambat musuh yang berusaha memasuki tempat persembunyiannya Putri Merak Jingga, tetapi akhirnya Putra Bandar Sakti tewas juga. Mahraja Hwa Loan lalu menawan Putri Merak Jingga dan Raja Sakti. Diperlihatkan Putri Merak Jingga dimasukkan ke dalam keranda kaca. (02.30-

03.05).

\section{Scene ke 13}

Pada waktu yang bersamaan Alang Jermal sedang dalam perjalanan pulang dengan membawa ikan kahyangan untuk Putri Merak Jingga. Ia sangat terkejut dan heran melihat istana telah berubah dan ia menjadi lebih terkejut dan heran melihat Putri Merak Jingga terkurung di dalam keranda kaca, tetapi tiba-tiba muncul Maharaja Hwa Loan dengan pedang terhunus. Alang Jermal dengan tenaga yang kuat luar biasa berhasil melempar Maharaja Hwa Loan ke luar istana yang kemudian jatuh ke laut. Untuk keselamatan Putri Merak Jingga, Alang Maharaja Hwan Loan sangat marah dan berseru dengan hebatnya "Hai raja di Raja Dewa di Langit jadikanlah aku seekor naga yang paling ganas". Seketika gelap gulita dan menyambarlah guruh tunggal yang membahana. Tubuh raja itu gaib dari pandangan mata, dan muncullah seekor naga yang perkasa Begitu dia muncul serta merta menyambar serta menelan keranda kaca yang berisikan Puteri Merak Jingga (03.05-03.25).

\section{Scene ke 14}

Alang Jermal langsung mengejar dan berhasil masuk ke dalam perut naga. Digambarkan di dalam perut naga ia mendapati Putri Merak Jingga dan berdualah mereka di dalam perut naga itu. Beberapa pekan kemudian sampailah Naga Hwa Loan ke negerinya lalu dimuntahkannya keranca kaca itu, tetapi dewi yang dirindukannya itu tidak juga muncul. Dengan sangat menyesal maka dihempaskannya dirinya kian kemari dan dikunyahnya keranda kaca itu sampai hancur seperti hatinya yang hancur luluh (03.25-03.45).

Scene ke 15

Sebenarnya ketika Naga Hwa Loan memuntahkan sisi perutnya, Alang 
Jermal dan Putri Merak Jingga menyelam dan bersembunyi di pantai yang sepi, kemudian mereka masuk ke dalam gua yang terletak di bukit yang sangat terjal. Sewaktu mereka dalam perjalanan pulang, mereka berjumpa dengan orang sekampungnya. Kawan-kawan mereka sangat gembira ketika menyambut kedatangan Putri Merak Jingga dan Alang Jermal sebagai satu-satunya keturunan Raja Petani yang diduga telah meninggal (03.45.04.00)

\section{Scene ke 16}

Tidak lama kemudian berlangsunglah pesta perkawinan antar Putri Merak Jingga dengan Alang Jermal dan sekaligus peresmian penobatan Putri Merak Jingga menjadi Ratu Petani didampingi suaminya Pangeran Alang Jermal. Diperlihatkan rakyat berpesta dan bersukaria dalam acara itu (04.0004.10).

\section{Scene ke 17}

Karena takut akan gangguan negeri Asing, Pangeran Alang Jermalpun memindahkan pusat kerajaan ke daerah yang lebih aman. Suatu tempat yang airnya memancar dari celah-celah batu. Dan mereka namailah tempat tersebut Pancuran Batu, yang lama• kelamaan berobah menjadi Pancurbatu (04.1004.20).

\section{Scene ke 18}

Suatu hari Pangeran Alang Jermal meminta izin istrinya untuk mencari ikan kayangan yang dibawanya tempo hari, khusus untuk Ratu Putri Merak
Jingga. Sesudah sekian hari akhirnya diketahuilah bahwa ikan itu berada dimakam Putra Bandar Sakti. Ketika peti itu dibuka terkejutlah mereka melihatnya, karena kepala ikan kayangan itu serupa dengan kepala Alang Jermal. Seketika itu juga ratu Putri Merak Jingga jatuh sakit yang mencemaskan Pangeran Alang Jermal. Akhirnya kecemasan pangeran Alang Jermal itu lenyap ketika diketahuinya bahwa penyakit isterinya adalah penyakit bersalin. Kemudian lahirlah anak mereka kembar tujuh semuanya putri. Dalam upacara penabalan nama diperlihatkan putri-putrinya yang dinamai sebagai berikut (04.20-04.30) :

1.Putri Sri Kuning

2.Putri Sri Putih

3.Putri Biru Suci.

4.Putri Merah Lembayung

5.Putri Merak Hijau

6.Putri Sri Merah

7.Putri Merah Hijau

\section{Concept art}

Concept art merupakan proses pengembangan unsur-unsur dalam film animasi antara lain karakter, lingkungan dan properti. Berikut pengembangan desain model 3D masing- masing objek yang dibutuhkan yaitu :

\section{Analisis Pra Produksi}

Dari proses tahap pra produksi yang telah dikerjakan maka diperoleh beberapa hal yang dapat dianalisis antara lain :

1. Pengembangan ide cerita

a. Cerita merupakan unsur yang sangat penting dalam film, tanpa cerita yang kuat film animasi akan 
memberikan kesan membingungkan, membosankan dan menimbulkan ketidakpuasan terhadap penonton.

b. Proses pembuatan cerita yang baik, secara langsung dipengaruhi oleh calon penonton yang dilihat dari aspek demografis dan psikologis

c. Dalam mengembangkan ide cerita, sebaiknya diambil dari cerita yang sudahdibukukan untuk lebih mempersingkat waktu pembuatan dan mempermudah dalam melanjutkan ke proses berikutnya yaitu penulisan skenario (scene per scene)

2. Penulisan skenario

a. Skenario merupakan rincian kejadian/adegan dari cerita yang dibagi ke dalam beberapa scene.

b. Skenario yang baik menggambarkan setiap adegan dengan detil dan dapat menghidupkan suasana cerita.

c. Dalam penulisan scenario untuk film animasi sebaiknya dibuat durasi untuk setiap scene sehingga mempermudah pengerjaan proses berikutnya yaitu pembuatan in between pada tahap produksi.

3. Proses manajerial

a. Proses manajerial mempengaruhi keberlangsungan pembuatan sebuah film.

b. Penyusunan kru merupakan bagian yang terpenting dari proses ini.

c. Pembatasan jumlah kru dapat mengurangi pengeluaran namun di sisi lain menambah waktu pengerjaan sehingga diperlukan penyusunan kru yang bisa memangkas biaya pra produksi tapi tanpa mengurangi kualitas hasil sebuah film animasi.

\section{Concept art}

a. Concept art merupakan proses pengembangan unsur-unsur dalam film animasi antara lain karakter, lingkungan ${ }^{-}$dan asset pendukung. Pengembangan bentuk karakter dalam film harus asli (original) dan menarik untuk diperankan dalam film animasi.

b. Bentuk setiap karakter dapat mencerminkan sifat-sifat meliputi melankolis, bijaksana, sentimental, optimis, asmara, mudah marah, keras kepala, tenang, kejam dan emosional.

c. Dalam membuat concept art, sebaiknya langsung dibuat dalam desain 3D bukan lagi dalam bentuk sketsa untuk lebih mempersingkat waktu pembuatan dan mempermudah dalam melanjutkan ke proses berikutnya yaitu pembuatan storyboard.

5. Storyboard

a. Storyboard atau papan gambar berupa urutan perencanaan dalam sebuah film yang digambarkan urutan-urutan kejadian berupa gambar sketsa sederhana.

b. Storyboard merupakan alat bantu narasi yang berupa visual, sehingga naskah cerita dan hasil visual dapat saling terkoordinasi Dalam pembuatan storyboard sebaiknya menggunakan desain 3D untuk lebih mempermudah proses animation pada tahap produksi.

\section{Hasil Pra Produksi}

Berdasarkan analisis terhadap permasalahan - permasalahan yang muncul dalam setiap proses, didapatkan hasil analisis berupa solusi perma- 
salahan yang direkomendasikan pada tahap pra produksi pembuatan film animasi 3D, di antaranya adalah :

1. Mengambil ide cerita dari cerita rakyat yang telah dibukukan untuk mempersingkat waktu pengembangan ide cerita sekaligus menggali kembali budaya bangsa.

2. Melakukan penulisan skenario disertai dengan durasi untuk setiap scene untuk mempermudah pengerjaan proses berikutnya.

3. Menyusun kru secara benar dengan mempertimbangkan biaya dan kualitas film yang akan dihasilkan.

4. Membuat concept art dalam desain 3D untuk mempersingkat waktu sekaligus mempermudah pengerjaan proses berikutnya.

5. Pembuatan storyboard dilakukan dengan menggunakan desain 3D untuk lebih mempermudah proses pada tahap berikutnya.

Dari beberapa solusi yang direkomendasikan pada tahap pra produksi diharapkan dapat membuat film animasi 3D lokal bisa bersaing dengan film animasi luar dalam beberapa hal antara lain :

1. Waktu pengerjaan yang lebih singkat

2. Biaya pembuatan yang lebih rendah

3. Kualitas yang lebih baik

\section{SIMPULAN}

Dari hasil penelitian tersebut maka diperoleh kesimpulan yaitu :

1. Proses pembuatan film animasi 3D pada tahap pra produksi terdiri dari pengembangan ide cerita, penulisan skenario, proses manajerial, concept art dan storyboard.
2. Proses perancangan dan pembuatan film animasi 3D pada tahap pra produksi dapat diterapkan pada pembuatan film animasi 3D Legenda Putri Merak Jingga. Diperoleh solusi terhadap permasalahan yang muncul pada setiap proses pra produksi.

\section{DAFTAR PUSTAKA}

[1] Hendratman, Hendi, (2016), The Magic of Adobe Photoshop, Edisi Ketiga, Informatika, Bandung

[2] Hendra, Andre, (2015), Membuat Animasi 3D dengan Autodesk Maya, Edisi Kesatu, Andi Offset Jakarta

[3] Jostonchoniv (2013), Pembuatan Film Animasi 3D Legenda Cerita Rakyat The Legend of Toba Lake, Jurnal Teknik dan Ilmu Komputer (2013).

[4] Hutomo, Anggara, (2016), Pemodelan dan Animasi 3D dengan 3DS Max, Edisi Kesatu, Andi Offset Jakarta

[5] Indra, Sukma, (2017), Membuat Karakter dan Animasi Game dengan 3ds Max, Edisi Kesatu, Andi Offset Jakarta 